\title{
Heart Disease and Cancer Deaths — Trends and Projections in the United States, 1969-2020
}

\author{
Hannah K. Weir, PhD; Robert N. Anderson, PhD; Sallyann M. Coleman King, MD, MSc; \\ Ashwini Soman, MPH; Trevor D. Thompson, BS; Yuling Hong, MD, MS, PhD; \\ Bjorn Moller, PhD; Steven Leadbetter, MS
}

\begin{abstract}
Suggested citation for this article: Weir HK, Anderson RN, Coleman King SM, Soman A, Thompson TD, Hong Y, et al. Heart Disease and Cancer Deaths - Trends and Projections in the United States, 1969-2020. Prev Chronic Dis 2016;13:160211. DOI: https://doi.org/10.5888/pcd13.160211.
\end{abstract}

\section{PEER REVIEWED}

\section{Abstract}

\section{Introduction}

Heart disease and cancer are the first and second leading causes of death in the United States. Age-standardized death rates (risk) have declined since the 1960s for heart disease and for cancer since the 1990s, whereas the overall number of heart disease deaths declined and cancer deaths increased. We analyzed mortality data to evaluate and project the effect of risk reduction, population growth, and aging on the number of heart disease and cancer deaths to the year 2020 .

\section{Methods}

We used mortality data, population estimates, and population projections to estimate and predict heart disease and cancer deaths from 1969 through 2020 and to apportion changes in deaths resulting from population risk, growth, and aging.

\section{Results}

We predicted that from 1969 through 2020, the number of heart disease deaths would decrease $21.3 \%$ among men $(-73.9 \%$ risk, $17.9 \%$ growth, $34.7 \%$ aging) and $13.4 \%$ among women $(-73.3 \%$ risk, $17.1 \%$ growth, $42.8 \%$ aging) while the number of cancer deaths would increase $91.1 \%$ among men $(-33.5 \%$ risk, $45.6 \%$ growth, $79.0 \%$ aging) and $101.1 \%$ among women (-23.8\% risk, $48.8 \%$ growth, $76.0 \%$ aging). We predicted that cancer would be- come the leading cause of death around 2016, although sex-specific crossover years varied.

\section{Conclusion}

Risk of death declined more steeply for heart disease than cancer, offset the increase in heart disease deaths, and partially offset the increase in cancer deaths resulting from demographic changes over the past 4 decades. If current trends continue, cancer will become the leading cause of death by 2020 .

\section{Introduction}

For most of the last century, the leading cause of death in the United States, as measured by actual deaths, was heart disease, followed by cancer (1). Cancer overtook heart disease to become the leading cause of death in 1 state (Alaska) in 1993, 2 states in 2000,8 states in 2005 , and 23 states in 2010, although the trend slowed or stopped in recent years $(2,3)$.

The age-standardized death rate approximates the population's risk of dying from a given cause and is used to compare risk of death between populations or within a population over time. Declining death rates indicate that the overall risk to the population of dying from heart disease or cancer decreased. However, agestandardized death rates do not convey the full extent of the burden of these diseases, because they effectively remove the influence of demographic changes related to population growth and changing age structure. Although the age-standardized death rate for heart disease began to decline in the late 1960s and for all cancers combined some 20 years later, the overall number of heart disease deaths declined and the number of cancer deaths increased $(1,4)$.

The number of deaths is a function of the population risk of being diagnosed and dying from that cause and the size and age structure of the population. The risk of death from heart disease and 
cancer generally increases with age, and over the past several decades the US population increased, particularly in the age group 65 years or older (5). These demographic changes are forecast to continue into this century as the cohort born after World War II, with increased longevity than earlier cohorts, enters the age groups most at risk of dying from heart disease and cancer.

The objective of this study was to use mortality data, current population estimates, and population projections to predict age-standardized death rates and death counts for heart disease and cancer from 1969, around the peak of heart disease death rates (risk), through 2020 and to apportion changes in deaths resulting from population risk reduction, population growth, and population aging (ie, shift in age distribution toward older ages and increased longevity).

\section{Methods}

\section{Source of data}

We obtained mortality data from 1969 through 2014 from the National Vital Statistics System (6).The underlying cause of death was assigned according to the International Classification of Disease (ICD) in use at the time of death, converted to ICD-10 (International Classification of Disease, Revision 10), and recoded to ensure comparability over time (7). For these analyses, we defined heart disease as rheumatic heart disease (I00-I09), hypertensive heart disease (I11), hypertensive heart and kidney disease (I13), acute myocardial infarction (I21-I22), other ischemic or coronary heart disease (I20, I23-I25), atrial fibrillation (I48), other arrhythmias (I47, I49), heart failure (I50), and other heart disease (I26-I146, I51); we defined cancer as malignant neoplasms (ICD10: $\mathrm{C} 00-97)$.

Bridged single-race population estimates based on the 2010 US Census were available through the Surveillance, Epidemiology, and End Results (SEER) Program (8). We obtained data on population projections of the resident population by race, age, and sex from 2015 through 2020 from the US Census Bureau's Population Projections Program (9). Population estimates and projections were used as the denominators in rate calculations.

\section{Trends in death rates, 1969-2014}

We performed statistical analyses using SEER Stat software, version 8.3.2 (Surveillance Research Program [http://seer.cancer.gov/ seerstat/]), calculating averaged, annual age-standardized death rates per 100,000 population and standardized to the 2000 population, by sex and race (all, white, black). We estimated trends in death rates from 1969 through 2014 using joinpoint regression (Joinpoint Trend Analysis Software, version 4.2.0.1, http://surveillance.cancer.gov/joinpoint/), where a maximum of 5 joined straight-line segments were fit on a logarithmic scale to the trends in annual death rates. We described the resulting trends by the slope of each line segment as the annual percentage change (APC), using $t$ tests (2-sided, $P<.05)$ to assess whether the APCs were significantly different from zero. We used the terms increase or decrease to describe significant trends and stable to describe nonsignificant trends.

Methods for projecting cancer death rates and counts are described in detail elsewhere (10). Briefly, to project age-standardized death rates and counts for 2015 through 2020, we used Nordpred software $(11,12)$, which uses an age-period-cohort regression model with data aggregated into six 5-year calendar periods (1985-1989, 1990-1994, 1995-1999, 2000-2004, 2005-2009, 2010-2014) and 15 age groups $(15-19,20-24,25-29,30-34$, 35-39, 40-44, 45-49, 50-54, 55-59, 60-64, 65-69, 70-74, 75-79, $80-84, \geq 85$ y). Separate models were constructed for heart disease causes of death and for leading cancer causes of death, by sex for all races combined. We based projections for all heart disease deaths and all cancer deaths on summed estimates among the individual disease categories. We obtained predicted death counts and age-standardized death rates by applying estimated age-specific death rates to the population projections for 2015 through 2020.

Methods to apportion the relative contribution to changes in the total number of new heart disease or cancer deaths each year that can be attributed to changes in population risk (including changes in diagnosis and treatment practices) and demographic changes related to population size and age structure are described elsewhere (10). Briefly, we generated 3 sets of data for each death year from 1969 through 2020. Baseline was defined as the number of deaths from heart disease or cancer that occurred in 1969 for men and women separately. We generated one set of data for the total number of cancer deaths that would have occurred each year if the population size and age structure remained the same as it was in 1969; this set reflects the effect of changes in population risk and is similar to the age-standardized death rate. A second set of data was generated for the total number of deaths that would have occurred if the age structure had remained the same as it was in 1969; this set reflects the effect of changes in risk and population growth. A third set of data was generated for the observed number of deaths that actually occurred and thus reflects the combined impact of changes in population risk, growth, and aging. The yearly difference between each set of death counts denotes the relative contribution to the overall change in the number of deaths since 1969 attributed to population risk, growth, and aging. A decline in risk results in negative death counts, because fewer deaths are attributed to risk compared with 1969, the baseline year. The opinions expressed by authors contributing to this journal do not necessarily reflect the opinions of the U.S. Department of Health and Human Services,
the Public Health Service, the Centers for Disease Control and Prevention, or the authors' affiliated institutions. 


\section{Results}

The percentage change in death rates for heart disease declined among men (68.4\%) and women (67.6\%) (Table 1). By race and sex, the percentage decline was $68.8 \%$ among white men, $67.6 \%$ among white women, $59.4 \%$ among black men, and $63.8 \%$ among black women. The APCs for heart disease death rates for all races combined declined from 1969 through 2014 for men and women. By race and sex, the APC was stable in white men from 2010 through 2014 and from 2011 through 2014 for black men and women. The APC continued to decrease among white women through 2014.

From 1969 through 2014, the overall cancer death rates declined among men $(21.9 \%)$ and women $(15.6 \%)$. By race and sex, the percentage change declined by $20.9 \%$ among white men, $14.5 \%$ among white women, $19.3 \%$ among black men, and $11.0 \%$ among black women. The APCs for cancer death rates increased between 1969 and 1990-1992 in men and women of both racial groups before declining in all groups beginning in the early 1990s through 2014.

In 1969, the risk of heart disease death (measured by the ASDR) was 2.8 times higher than the risk of cancer death among white men and 2.2 times higher among black males. In 2014, the risk of heart disease death was 1.1 times higher than the risk of cancer death among black men and lower (0.9) among white women. In 2009 , the cancer death rate surpassed that for heart disease among white women while actual deaths remained higher.

Table 2 and Figure 1 show the contributions to the changes in the total observed (1969-2014) and predicted (2015-2020) number of heart disease and cancer deaths by sex and year attributed to changes in population risk, growth, and aging by sex from the baseline (1969) through 2020. Compared with 1969, the number of heart disease deaths in 2020 is predicted to decrease by $21.3 \%$ among men (-73.9\% risk, $17.9 \%$ growth, $34.7 \%$ aging) and $13.4 \%$ among women ( $-73.3 \%$ risk, $17.1 \%$ growth, $42.8 \%$ aging). Cancer deaths are predicted to increase by $91.1 \%$ among men $(-33.5 \%$ risk, $45.6 \%$ growth, $79.0 \%$ aging) and $101.1 \%$ among women ( $-23.8 \%$ risk, $48.8 \%$ growth, $76.0 \%$ aging). In 2017 , more cancer deaths are predicted than heart disease deaths in men $(321,107 \mathrm{vs}$ $319,793)$. In 2015 , similar numbers of cancers deaths $(281,683)$ as heart disease deaths $(281,675)$ are predicted for women.

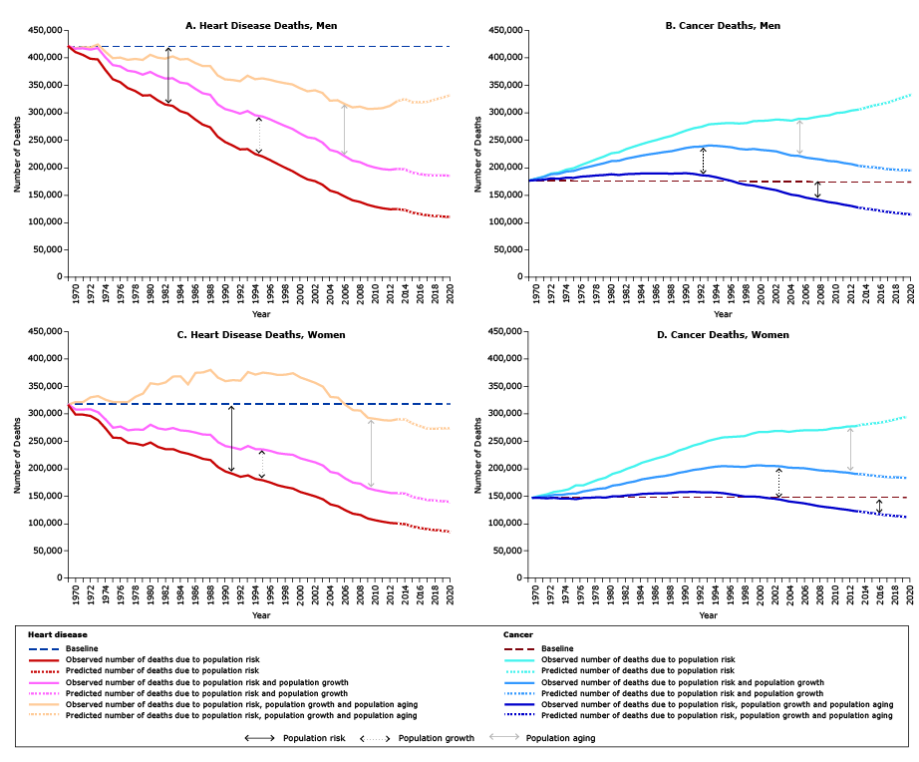

Figure 1. Trends in observed (1969-2014) and predicted (2015-2020) heart disease and cancer deaths attributed to the average person's risk of dying from the disease (ie, population risk, accounting for such factors as changes in diagnostic and treatment practices), population growth, and population aging, by sex. The blue dashed line (baseline) is the number of deaths from heart disease or cancer that occurred in 1969. The dark yellow (1969-2014) and light yellow (2015-2020) line represents the total number of deaths that would have occurred each year if the population size and age structure remained the same as it was in 1969; this line reflects the effect of changes in population risk. The black (1969-2014) and gray (2015-2020) line represents the total number of deaths that would have occurred if the age structure had remained the same as it was in 1969; this line reflects the effect of changes in risk and population growth. The dark orange (1969-2014) and light orange (2015-2020) line represents the expected number of deaths that actually occurred and thus reflects the combined impact of changes in population risk, growth, and aging. A. Heart disease deaths among men. The number of heart disease deaths attributed to risk declined while the number of heart disease deaths resulting from population growth and aging increased. Observed heart disease deaths declined from 1969 through 2014 and are predicted to increase through 2020, primarily because of an aging population. B. Number of cancer deaths among men. The number of cancer deaths attributed to risk increased from 1969 through 2000 and declined from 2000 forward. The number of cancer deaths resulting from population growth and aging increased. Observed cancer deaths increased from 1969 through 2014 and are predicted to continue to increase through 2020, primarily because of an aging population. C. Number of heart disease deaths among women. The number of heart disease deaths attributed to risk declined while the number of heart disease deaths resulting from population growth and aging increased. Observed heart disease deaths increased from 1969 through 1995, primarily because of an aging population. Observed heart disease deaths are predicted to continue to decrease through 2020 , primarily because of continued risk reduction. D. Number of cancer deaths among women. The number of cancer deaths attributed to risk increased from 1969 through 2000 and declined from 2000 forward. The number of cancer deaths resulting from population growth and aging increased. Observed cancer deaths increased from 1969 through 2015 and are predicted to continue to increase through 2020 , primarily because of an aging population.

The opinions expressed by authors contributing to this journal do not necessarily reflect the opinions of the U.S. Department of Health and Human Services, the Public Health Service, the Centers for Disease Control and Prevention, or the authors' affiliated institutions. 
Figure 2 shows the observed (1969-2014) and predicted (2015-2020) number of deaths and death rates for heart disease and cancer by year for all races and both sexes combined. From 2015 to 2020, we predict the number of heart disease deaths overall to stabilize and cancer deaths to increase and surpass heart disease deaths. For 2016, we predict more deaths from cancer than from heart disease $(591,426$ vs 587,329$)$. In 2020 , we predict a total of 627,620 cancer deaths vs 572,415 heart disease deaths.

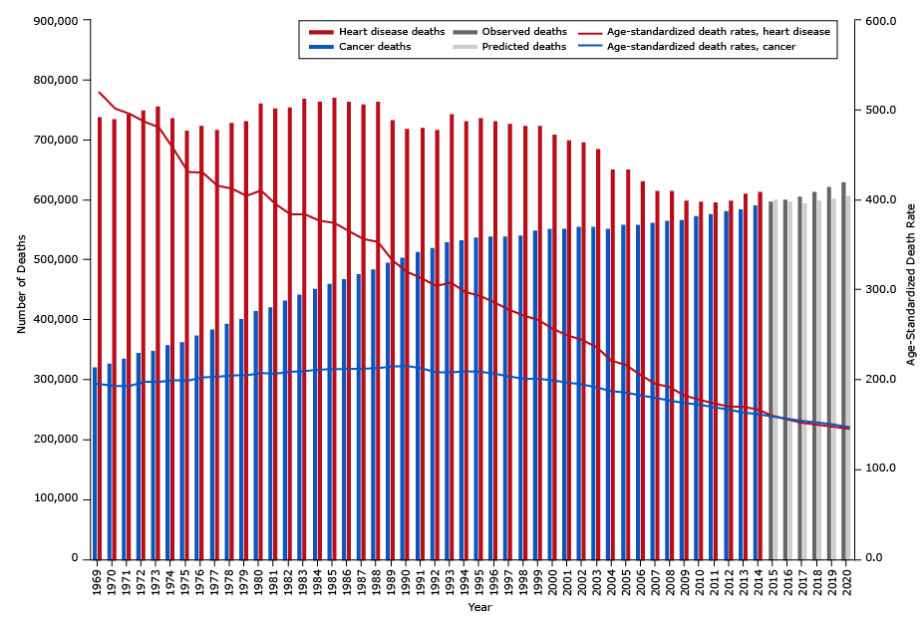

Figure 2. Age-standardized death rates (ASDR) and the observed and predicted number of cancer and heart disease deaths from 1969 through 2020 for men and women combined.

\section{Discussion}

Our projections indicate that cancer will soon become the leading cause of death in the United States if trends in risk of death from cancer and heart disease and population growth and aging continue. In 1969, there were more than twice as many heart disease deaths as cancer deaths. The decline in heart disease rates (risk) began earlier and was steeper than the decline in risk of death from cancer, which occurred approximately 20 years later. The magnitude of heart disease risk reduction has offset the increase in heart disease deaths from population growth and aging, while the decline in risk of cancer deaths only partially offset the increase in cancer deaths resulting from demographic changes related to population growth and aging. These findings are similar among black and white Americans.

Several factors contributed to the decline in heart disease risk. In 1964, the first Surgeon General's report on smoking and health (13) linked smoking and lung cancer, and a later report linked smoking with the risk of heart attack and stroke, noting that smokers had about twice the risk of dying from heart disease than lifetime nonsmokers (14). Among smokers, the reduction in ex- cess risk of death from heart disease occurs soon after cessation and is reduced by about half after only one year of smoking abstinence (15). After 15 years of cessation, the risk of death is slightly elevated, but similar to those who never smoked, supporting the hypothesis that the inflammatory component of cardiovascular disease is reversible. Although the declining risk of dying from heart disease has paralleled the decline in smoking prevalence, treatment of cardiovascular disease risk factors has also improved. Cohorts who were aged 50 to 60 years in the 1970s had a $43 \%$ lower 10 -year cumulative mortality than similar cohorts who reached that age in the 1950s, with significant reductions in cardiovascular disease risk factors such as lower serum cholesterol levels, lower systolic blood pressure, and better overall blood pressure control (16). From 1980 to 2000, approximately half of the decline in heart disease death was attributed to improved treatment after acute myocardial infarction or unstable angina, secondary prevention post-myocardial infarction, treatment of heart failure, and revascularization for chronic angina. The remaining decline was attributed to further reductions in the major risk factors - total cholesterol levels, high blood pressure, and smoking and increased physical activity (17). Further reduction in the risk of heart disease deaths may have been tempered by increases in body mass index and the prevalence of diabetes (18).

The overall risk of death from heart disease declined in both black and white Americans and, based on our model, is predicted to continue to decline through 2020. Since 1969, the reduction in risk among men has more than offset the increase in heart disease deaths caused by population growth and aging. This reduction in risk has resulted in an overall decline in the observed number of heart disease deaths. However, we predict that the number of heart disease deaths will stabilize or increase slightly in men from 2015 to 2020 as further risk reduction is no longer able to offset the increase in heart disease deaths caused by demographic trends, particularly trends in population aging. A reduction in the number of heart disease deaths among women began more recently and is predicted to continue through 2020.

The overall risk of dying from cancer increased throughout much of the latter part of the last century and is consistent with an increase in the incidence of 4 leading cancers: cancers of the lung and bronchus, colon and rectum, prostate, and female breast (8). Collectively, these cancers accounted for almost $50 \%$ of all cancer deaths in the United States. The cancer death rate began to decline in the early 1990s and was largely driven by a decline in deaths from cancers of the lung and prostate in men, breast cancer in women, and a continued decline in colorectal cancer deaths in both men and women that began in the mid-1980s. Lung cancer death rates in women began to decline in the early 2000 s, approximately a decade after the decline began in men.

\footnotetext{
The opinions expressed by authors contributing to this journal do not necessarily reflect the opinions of the U.S. Department of Health and Human Services, the Public Health Service, the Centers for Disease Control and Prevention, or the authors' affiliated institutions.
} 
The decline in lung cancer death rates in both men and women parallels a reduction in tobacco use in each group, offset by a latency period of several decades (19). Death rates from other tobacco-related cancers have declined as well, likely the result of reduced smoking prevalence as subsequent Surgeon General reports found convincing evidence for a direct causal relationship (20). Access to quality health care, including early diagnosis through screening, timely follow-up, and evidence-based treatments, is believed to have resulted in increased survival accompanied by reduced mortality from colorectal cancer and, to a lesser extent, female breast cancer and prostate cancer (21).

The risk of dying from cancer increased among men and women throughout the early 1990s before declining, with further risk reduction predicted through 2020. The increase in the risk of death from cancer from 1969 to the early 1990s exacerbated the increase in cancer deaths caused by demographic changes in population growth and aging, resulting in an overall increase in the observed number of cancer deaths. As the risk of cancer deaths began to decline, the number of deaths continued to increase, although at a slower rate. Underlying these trends in deaths is the predicted number of incident cases of cancer, which is expected to increase by more than 20\% from 2010 through 2020, whereas the overall risk of being diagnosed with cancer is predicted to remain stable (22).

The risk of dying from heart disease and cancer generally increases with age and, as a result, the numbers of heart disease and cancer deaths increase with the growth and aging of the US population. These demographic influences are likely to continue, because the US population is expected to increase by $10 \%$ from 2010 to 2020 , with the proportion of the population 65 years of age or older increasing from $13 \%$ to $16 \%(5)$. The reduction in risk of death from cancer started later than the reduction in risk of death from heart disease and has not been as rapid. Our models estimated that the number of deaths from cancer would surpass the number of deaths from heart disease around 2016, because heart disease deaths were predicted to stabilize or increase slightly in men, and cancer deaths were predicted to continue to increase. Heart disease deaths actually increased in 2013 and again in 2014, somewhat earlier than predicted.

These results are subject to several limitations. This study used methods based on age-period-cohort models that identify trends in younger birth cohorts and extrapolate these trends to future older cohorts (12). Studies have validated these methods by using long-term cancer incidence data but not heart disease or cancer death data. These predictions are based on trends in risk during the past 10 to 30 years; trends in recent years may differ from longterm trends. As such, predictions of heart disease and cancer deaths may be overestimates, because the risk components in these models do not account for potential recent advances in primary prevention and treatment or national initiatives, such as CDC's Screen for Life: National Colorectal Cancer Action Campaign (http://www.cdc.gov/cancer/colorectal/sfl/) or the Million Hearts project (http://millionhearts.hhs.gov/). At the same time, our predictions may be underestimates because the risk component may not fully account for the potential effect of increased prevalence of obesity and diabetes on risk for cardiovascular disease or for cancers such as pancreatic cancer, which is increasing and now is the fourth leading cause of cancer-related deaths in the United States (23).

The population projections used in these predictions are themselves forecasts of the population size and age composition based on assumptions on future births, deaths, and migration. Furthermore, overall life expectancy in the United States is improving even as disparities by race and socioeconomic factors are increasing (24); these trends are likely to affect population projections. Possible misclassification of underlying cause of death may contribute to imprecision in our estimates.

To counter the anticipated growth in the number of heart disease and cancer deaths, increase the health span of an aging population, and reduce the incidence of heart disease and cancer, a greater emphasis on primary prevention and improved treatment is needed. CDC estimates that each year approximately 91,000 premature deaths from heart disease and 84,000 premature deaths from cancer are potentially preventable (25). Heart disease and cancer share numerous related risk factors, including tobacco use, obesity, and physical inactivity. Further reductions in deaths might yet be achievable if Healthy People 2020 objectives related to risk factors, early diagnosis, and access to health care are met (26).

\section{Acknowledgments}

We thank Ms Jessica King for assistance in the joinpoint analyses. The findings and conclusions in this report are those of the authors and do not necessarily represent the official position of the Centers for Disease Control and Prevention.

\section{Author Information}

Corresponding Author: Hannah K. Weir, PhD, Division of Cancer Prevention and Control, Centers for Disease Control and Prevention, 4770 Buford Hwy, MS F76, Atlanta, GA 30341. Telephone: 770-488-3006. E-mail: hbw4@cdc.gov.

Author Affiliations: Robert N. Anderson, Division of Vital Statistics, National Center for Health Statistics, Centers for Disease Control and Prevention, Hyattsville, Maryland; Sallyann M. Coleman King, Yuling Hong, Division for Heart Disease and

The opinions expressed by authors contributing to this journal do not necessarily reflect the opinions of the U.S. Department of Health and Human Services, the Public Health Service, the Centers for Disease Control and Prevention, or the authors' affiliated institutions. 
Stroke Prevention, National Center for Chronic Disease Prevention and Health Promotion, Centers for Disease Control and Prevention, Atlanta, Georgia; Ashwini Soman, Northrop Grumman Corporation, Atlanta, Georgia; Trevor D. Thompson, Steven Leadbetter, Division of Cancer Prevention and Control, National Center for Chronic Disease Prevention and Health Promotion, Centers for Disease Control and Prevention, Atlanta, Georgia; Bjorn Moller, Department of Registration, Cancer Registry of Norway, Oslo, Norway.

\section{References}

1. Hoyert DL. 75 years of mortality in the United States, 1935-2010. NCHS Data Brief 2012;(88):1-8.

2. Centers for Disease Control and Prevention, National Center for Health Statistics. Compressed mortality file 1979-1998. CDC WONDER online database. http://wonder.cdc.gov/cmficd9.html. Accessed July 5, 2016.

3. Deaths, percent of total deaths, and death rates for the 15 leading causes of death: United States and each State, 1999-2013. http://www.cdc.gov/nchs/nvss/mortality/ lcwk9.htm. Accessed July 5, 2016.

4. Centers for Disease Control and Prevention. Decline in deaths from heart disease and stroke-United States, 1900-1999. MMWR Morb Mortal Wkly Rep 1999;48(30):649-56. http:// www.cdc.gov/mmwr/preview/mmwrhtml/mm4830a1.htm Accessed July 5, 2016

5. The next four decades: the older population in the United States: 2010 to 2050 . Current population report P25-1138. Washington (DC): US Census Bureau; 2010. http:// www.census.gov/prod/2010pubs/p25-1138.pdf. Accessed July 5, 2016.

6. National Vital Statistics System. Centers for Disease Control and Prevention. http://www.cdc.gov/nchs/nvss.htm. Accessed July 5, 2016.

7. SEER cause of death recode. http://seer.cancer.gov/codrecode/. Accessed July 5, 2016.

8. Howlader N, Noone AM, Krapcho M, editors. SEER cancer statistics review, 1975-2012. National Cancer Institute. http:// seer.cancer.gov/csr/1975_2012/. Based on November 2014 SEER data submission. Accessed July 5, 2016.

9. 2014 National population projections: downloadable files. http://www.census.gov/population/projections/data/national/ 2014/downloadablefiles.html. Accessed July 5, 2016.

10. Weir HK, Thompson TD, Soman A, Møller B, Leadbetter S, White MC. Meeting the Healthy People 2020 objectives to reduce cancer mortality. Prev Chronic Dis 2015;12:E104.
11. Møller B, Fekjaer H, Hakulinen T, Tryggvadóttir L, Storm $\mathrm{HH}$, Talbäck M, et al. Prediction of cancer incidence in the Nordic countries up to the year 2020. Eur J Cancer Prev 2002; 11(Suppl 1):S1-96.

12. Møller B, Fekjaer H, Hakulinen T, Sigvaldason H, Storm HH, Talbäck M, et al. Prediction of cancer incidence in the Nordic countries: empirical comparison of different approaches. Stat Med 2003;22(17):2751-66.

13. US Surgeon General's Advisory Committee on Smoking and Health. Smoking and health. PHS publication no. 1103. Washington (DC): US Public Health Service; 1964.

14. The Surgeon General's 1990 report on the health benefits of smoking cessation executive summary - preface. http:// www.cdc.gov/mmwr/preview/mmwrhtml/00001800.htm. Accessed September 19, 2016.

15. Bakhru A, Erlinger TP. Smoking cessation and cardiovascular disease risk factors: results from the Third National Health and Nutrition Examination Survey. PLoS Med 2005;2(6):e160.

16. Sytkowski PA, Kannel WB, D’Agostino RB. Changes in risk factors and the decline in mortality from cardiovascular disease. The Framingham Heart Study. N Engl J Med 1990; 322(23):1635-41.

17. Ford ES, Ajani UA, Croft JB, Critchley JA, Labarthe DR, Kottke TE, et al. Explaining the decrease in U.S. deaths from coronary disease, 1980-2000. N Engl J Med 2007; 356(23):2388-98.

18. Capewell S, Ford ES, Croft JB, Critchley JA, Greenlund KJ, Labarthe DR. Cardiovascular risk factor trends and potential for reducing coronary heart disease mortality in the United States of America. Bull World Health Organ 2010; 88(2):120-30.

19. Jemal A, Thun MJ, Ries LA, Howe HL, Weir HK, Center MM, et al. Annual report to the nation on the status of cancer, 1975-2005, featuring trends in lung cancer, tobacco use, and tobacco control. J Natl Cancer Inst 2008;100(23):1672-94.

20. US Department of Health and Human Services. The health consequences of smoking — 50 years of progress. Atlanta (GA): US Department of Health and Human Services, Centers for Disease Control and Prevention; 2014.

21. Cho H, Mariotto AB, Schwartz LM, Luo J, Woloshin S. When do changes in cancer survival mean progress? The insight from population incidence and mortality. J Natl Cancer Inst Monogr 2014;2014(49):187-97.

22. Weir HK, Thompson TD, Soman A, Møller B, Leadbetter S. The past, present, and future of cancer incidence in the United States: 1975 through 2020. Cancer 2015;121(11):1827-37.

23. Ryerson AB, Eheman CR, Altekruse SF, Ward JW, Jemal A, Sherman RL, et al. Annual report to the nation on the status of cancer, 1975-2012, featuring the increasing incidence of liver cancer. Cancer 2016;122(9):1312-37.

\footnotetext{
The opinions expressed by authors contributing to this journal do not necessarily reflect the opinions of the U.S. Department of Health and Human Services, the Public Health Service, the Centers for Disease Control and Prevention, or the authors' affiliated institutions.
} 
24. Olshansky SJ, Antonucci T, Berkman L, Binstock RH, Boersch-Supan A, Cacioppo JT, et al. Differences in life expectancy due to race and educational differences are widening, and many may not catch up. Health Aff (Millwood) 2012;31(8):1803-13.

25. Yoon PW, Bastian B, Anderson RN, Collins JL, Jaffe HW. Potentially preventable deaths from the five leading causes of death — United States, 2008-2010. MMWR Morb Mortal Wkly Rep 2014;63(17):369-74.

26. About Healthy People. Washington (DC): US Department of Health and Human Services; 2012. https:// www.healthypeople.gov/2020/About-Healthy-People. Accessed July 5, 2016. 


\section{Tables}

Table 1. Age-Standardized Death Rates and Overall Percentage Change and the Annual Percentage Change in Age-Standardized Death Rates by Joinpoint Analyses for Cancer and Heart Disease, by Sex and Race, 1969-2014

\begin{tabular}{|c|c|c|c|c|c|c|c|c|c|c|c|c|}
\hline \multirow[b]{2}{*}{ Variable } & \multirow[b]{2}{*}{$\begin{array}{c}\text { ASDR 1969/ } \\
2014\end{array}$} & \multirow[b]{2}{*}{$\begin{array}{c}\% \text { Change, } \\
\text { 1969-2014 }\end{array}$} & \multicolumn{2}{|c|}{ Trend 1} & \multicolumn{2}{|c|}{ Trend 2} & \multicolumn{2}{|c|}{ Trend 3} & \multicolumn{2}{|c|}{ Trend 4} & \multicolumn{2}{|c|}{ Trend 5} \\
\hline & & & Start Year & $\begin{array}{c}\text { APC } \\
(P \text { Value })\end{array}$ & Start Year & $\begin{array}{c}\text { APC } \\
(P \text { Value })\end{array}$ & Start Year & $\begin{array}{c}\text { APC } \\
(P \text { Value })\end{array}$ & Start Year & $\begin{array}{c}\text { APC } \\
(P \text { Value })\end{array}$ & Start Year & $\begin{array}{c}\text { APC } \\
\text { (P Value) }\end{array}$ \\
\hline \multicolumn{13}{|l|}{ Heart disease } \\
\hline All & $520.4 / 166.6$ & -68.0 & 1969 & $(<.001)$ & 1977 & $-1.1(.02)$ & 1983 & $\begin{array}{r}-2.4 \\
(<.001)\end{array}$ & 2002 & $\begin{array}{r}-4.2 \\
(<.001)\end{array}$ & 2009 & $\begin{array}{l}-1.7 \\
(.001)\end{array}$ \\
\hline All men & $668.2 / 211.1$ & -68.4 & 1969 & $(<.001)$ & 1978 & $-1.3(.04)$ & 1983 & $(<.001)$ & 2002 & $\left(\begin{array}{r}-4.1 \\
(<.001)\end{array}\right.$ & 2009 & $\begin{array}{l}-1.5 \\
(.003)\end{array}$ \\
\hline All women & $404.4 / 131.1$ & -67.6 & 1969 & $\begin{array}{r}-3.1 \\
(<.001) \\
\end{array}$ & 1977 & $-0.6(.21)$ & 1983 & $\left(\begin{array}{r}-2.2 \\
(<.001)\end{array}\right.$ & 2002 & $\begin{array}{r}-4.4 \\
(<.001) \\
\end{array}$ & 2010 & $-1.6(.05)$ \\
\hline All white & $518.8 / 165.3$ & -68.1 & 1969 & $\begin{array}{r}-2.8 \\
(<.001) \\
\end{array}$ & 1977 & $-1.3(.01)$ & 1983 & $(<.001)$ & 2002 & $\begin{array}{r}-4.2 \\
(<.001) \\
\end{array}$ & 2009 & $\begin{array}{l}-1.6 \\
(.004)\end{array}$ \\
\hline White men & $673.1 / 210.0$ & -68.8 & 1969 & $\left(<\begin{array}{r}-2.0 \\
(<.001)\end{array}\right.$ & 1987 & $-4.2(.03)$ & 1990 & $(<.001)$ & 1997 & $\begin{array}{r}-3.6 \\
(<.001)\end{array}$ & 2010 & $-1.1(.09)$ \\
\hline White women & $398.5 / 129.2$ & -67.6 & 1969 & $\begin{array}{r}-3.0 \\
(<.001) \\
\end{array}$ & 1977 & $-0.8(.15)$ & 1983 & $\begin{array}{r}-2.3 \\
(<.001)\end{array}$ & 2002 & $\begin{array}{r}-4.4 \\
(<.001) \\
\end{array}$ & 2009 & $\begin{array}{l}-2.0 \\
(.002) \\
\end{array}$ \\
\hline All black & $544.0 / 207.1$ & -61.9 & 1969 & $(<.001)$ & 1977 & $-0.3(.27)$ & 1986 & $(<.001)$ & 2002 & $\begin{array}{r}-4.2 \\
(<.001)\end{array}$ & 2011 & $-1.0(.36)$ \\
\hline Black men & $643.7 / 261.6$ & -59.4 & 1969 & $\left(<\begin{array}{r}-2.2 \\
(<.001)\end{array}\right.$ & 1976 & $-0.4(.02)$ & 1987 & $\left(<\begin{array}{r}-2.2 \\
(<.001)\end{array}\right.$ & 2003 & $\begin{array}{r}-4.1 \\
(<.001)\end{array}$ & 2011 & $-0.7(.52)$ \\
\hline Black women & $463.7 / 167.9$ & -63.8 & 1969 & $\begin{array}{r}-3.2 \\
(<.001)\end{array}$ & 1976 & $-0.3(.15)$ & 1986 & $\begin{array}{r}-1.8 \\
(<.001)\end{array}$ & 2002 & $\begin{array}{r}-4.6 \\
(<.001) \\
\end{array}$ & 2011 & $-1.2(.33)$ \\
\hline \multicolumn{13}{|l|}{ Cancer } \\
\hline All & $198.6 / 161.2$ & -18.8 & 1969 & $0.2(.32)$ & 1974 & $\begin{array}{r}0.5 \\
(<.001)\end{array}$ & 1990 & $-0.3(.57)$ & 1993 & $\begin{array}{r}-1.1 \\
(<.001) \\
\end{array}$ & 2002 & $\begin{array}{r}-1.5 \\
(<.001)\end{array}$ \\
\hline All men & $247.6 / 193.3$ & -21.9 & 1969 & $\begin{array}{r}0.8 \\
(<.001) \\
\end{array}$ & 1980 & $\begin{array}{r}0.3 \\
(<.001) \\
\end{array}$ & 1990 & $-0.5(.38)$ & 1993 & $\begin{array}{r}-1.5 \\
(<.001) \\
\end{array}$ & 2001 & $\begin{array}{r}-1.8 \\
(<.001) \\
\end{array}$ \\
\hline All women & $163.2 / 137.8$ & -15.6 & 1969 & $-0.3(.03)$ & 1975 & $\begin{array}{r}0.6 \\
(<.001)\end{array}$ & 1990 & $-0.2(.55)$ & 1994 & $\begin{array}{r}-0.8 \\
(<.001)\end{array}$ & 2002 & $\begin{array}{l}-1.4 \\
<.001\end{array}$ \\
\hline All white & 196.2/161.7 & -17.6 & 1969 & $0.1(.60)$ & 1974 & $\begin{array}{r}0.4 \\
(<.001)\end{array}$ & 1991 & $\begin{array}{r}-0.9 \\
(<.001)\end{array}$ & 2001 & $\begin{array}{r}-1.4 \\
(<.001) \\
\end{array}$ & - & - \\
\hline White men & $244.5 / 193.3$ & -20.9 & 1969 & $\begin{array}{r}0.7 \\
(<.001) \\
\end{array}$ & 1980 & $\begin{array}{r}0.2 \\
(<.001) \\
\end{array}$ & 1992 & $\begin{array}{r}-1.4 \\
(<.001) \\
\end{array}$ & 2002 & $\begin{array}{r}-1.7 \\
(<.001) \\
\end{array}$ & - & - \\
\hline White women & $161.9 / 138.4$ & -14.5 & 1969 & $\begin{array}{r}-0.3 \\
(.076)\end{array}$ & 1975 & $\begin{array}{r}0.6 \\
(<.001)\end{array}$ & 1991 & $\begin{array}{r}-0.6 \\
(<.001) \\
\end{array}$ & 2001 & $\begin{array}{r}-1.3 \\
(<.001) \\
\end{array}$ & - & - \\
\hline All black & $226.0 / 186.3$ & -17.6 & 1969 & $\begin{array}{r}1.2 \\
(<.001) \\
\end{array}$ & 1984 & $\begin{array}{r}0.7 \\
(<.001) \\
\end{array}$ & 1991 & $-0.8(.04)$ & 1995 & $\begin{array}{r}-1.6 \\
(<.001) \\
\end{array}$ & 2001 & $(<.001)$ \\
\hline Black men & $289.7 / 233.8$ & -19.3 & 1969 & $\begin{array}{r}1.9 \\
(<.001)\end{array}$ & 1982 & $\begin{array}{r}1.0 \\
(<.001)\end{array}$ & 1990 & $-0.2(.79)$ & 1993 & $\left(\begin{array}{r}-2.0 \\
(<.001)\end{array}\right.$ & 2001 & $\begin{array}{r}-2.7 \\
(<.001)\end{array}$ \\
\hline Black women & $176.3 / 156.9$ & -11.0 & 1969 & $0.1(.82)$ & 1975 & $\begin{array}{r}1.0 \\
(<.001)\end{array}$ & 1991 & $\begin{array}{r}-0.6 \\
(.004)\end{array}$ & 1999 & $\left(\begin{array}{r}-1.6 \\
(<.001)\end{array}\right.$ & - & - \\
\hline
\end{tabular}

Abbreviations: -, no change from trend 4; APC, annual percentage change; ASDR, age-standardized death rates, expressed per 100,000 persons; PC, percentage change.

The opinions expressed by authors contributing to this journal do not necessarily reflect the opinions of the U.S. Department of Health and Human Services, the Public Health Service, the Centers for Disease Control and Prevention, or the authors' affiliated institutions. 
Table 2. Observed (1969-2014) and Predicted (2015-2020) Deaths From Heart Disease and Cancer, by Sex, Apportioned Into Changes Resulting From Population Risk, Population Growth, or Population Aging Relative to 1969 (Baseline) ${ }^{\text {a }}$

\begin{tabular}{|c|c|c|c|c|c|c|c|c|}
\hline \multirow[b]{2}{*}{ Year of Death } & \multicolumn{4}{|c|}{ Male } & \multicolumn{4}{|c|}{ Female } \\
\hline & Total & Risk $^{b}$ & Growth $^{c}$ & Aging $^{d}$ & Total & Risk $^{b}$ & Growth $^{c}$ & Aging $^{d}$ \\
\hline \multicolumn{9}{|l|}{ Heart disease } \\
\hline 1969 & 421,729 & 0 & 0 & 0 & 317,341 & 0 & 0 & 0 \\
\hline 1975 & 399,436 & $-60,516$ & 25,660 & 12,562 & 323,216 & $-61,349$ & 18,193 & 49,030 \\
\hline 1980 & 405,574 & $-89,778$ & 42,441 & 31,182 & 355,364 & $-70,163$ & 32,410 & 75,776 \\
\hline 1985 & 398,101 & $-123,117$ & 54,444 & 45,045 & 353,282 & $-90,515$ & 41,505 & 84,951 \\
\hline 1990 & 360,729 & $-175,024$ & 60,056 & 53,968 & 359,225 & $-123,027$ & 46,308 & 118,603 \\
\hline 1995 & 362,663 & $-201,350$ & 72,780 & 69,504 & 374,807 & $-139,128$ & 56,541 & 140,053 \\
\hline 2000 & 344,766 & $-236,214$ & 76,871 & 82,379 & 365,935 & $-160,387$ & 61,432 & 147,549 \\
\hline 2005 & 322,816 & $-267,501$ & 74,560 & 94,027 & 329,238 & $-186,281$ & 59,671 & 138,507 \\
\hline 2010 & 307,365 & $-292,876$ & 71,356 & 107,156 & 290,296 & $-212,098$ & 54,998 & 130,055 \\
\hline 2013 & 321,329 & $-297,415$ & 73,479 & 123,535 & 289,753 & $-217,777$ & 55,393 & 134,796 \\
\hline 2014 & 325,050 & $-298,886$ & 74,109 & 128,098 & 289,255 & $-219,159$ & 55,731 & 135,342 \\
\hline $2015^{\mathrm{e}}$ & 319,035 & $-303,795$ & 72,845 & 128,257 & 281,675 & $-223,641$ & 54,188 & 133,787 \\
\hline $2016^{\mathrm{e}}$ & 319,315 & $-306,212$ & 72,940 & 130,858 & 278,222 & $-226,132$ & 53,878 & 133,135 \\
\hline $2017^{\mathrm{e}}$ & 319,793 & $-308,629$ & 72,967 & 133,727 & 274,913 & $-228,624$ & 53,511 & 132,685 \\
\hline $2018^{\mathrm{e}}$ & 324,027 & $-309,659$ & 73,837 & 138,121 & 274,964 & $-229,917$ & 53,823 & 133,717 \\
\hline $2020^{\mathrm{e}}$ & 331,711 & $-311,719$ & 75,471 & 146,230 & 274,897 & $-232,504$ & 54,354 & 135,706 \\
\hline Change from 1969 to $2020, \%$ & -21.3 & -73.9 & 17.9 & 34.7 & -13.4 & -73.3 & 17.1 & 42.8 \\
\hline \multicolumn{9}{|l|}{ Cancer } \\
\hline 1969 & 175,404 & 0 & 0 & 0 & 146,360 & 0 & 0 & 0 \\
\hline 1975 & 198,586 & 5,438 & 12,849 & 4,895 & 171,143 & $-2,128$ & 10,245 & 16,666 \\
\hline 1980 & 225,943 & 12,260 & 24,002 & 14,276 & 190,554 & 2,939 & 19,570 & 21,685 \\
\hline 1985 & 246,917 & 14,237 & 34,561 & 22,715 & 214,646 & 7,913 & 28,238 & 32,135 \\
\hline 1990 & 268,292 & 14,723 & 46,283 & 31,882 & 237,047 & 10,734 & 37,450 & 42,504 \\
\hline 1995 & 281,635 & 4,331 & 59,391 & 42,509 & 256,852 & 8,839 & 49,257 & 52,396 \\
\hline 2000 & 286,072 & $-10,514$ & 68,316 & 52,866 & 267,008 & 1,894 & 58,041 & 60,713 \\
\hline 2005 & 290,417 & $-25,278$ & 72,560 & 67,731 & 268,886 & $-8,046$ & 62,978 & 67,594 \\
\hline 2010 & 301,032 & $-38,505$ & 75,803 & 88,331 & 273,706 & $-18,104$ & 67,000 & 78,450 \\
\hline 2013 & 307,553 & $-46,564$ & 76,036 & 102,676 & 277,319 & $-23,957$ & 67,769 & 87,146 \\
\hline 2014 & 311,285 & $-48,486$ & 76,568 & 107,799 & 280,401 & $-25,333$ & 68,699 & 90,675 \\
\hline $2015^{\mathrm{e}}$ & 315,189 & $-50,251$ & 77,304 & 112,733 & 281,683 & $-27,350$ & 68,825 & 93,848 \\
\hline $2016^{\mathrm{e}}$ & 317,789 & $-52,385$ & 77,677 & 117,093 & 283,162 & $-29,144$ & 69,241 & 96,706 \\
\hline
\end{tabular}

a Values are number unless otherwise noted.

${ }^{\mathrm{b}}$ Changes in deaths because of change in population risk of death.

${ }^{c}$ Changes in deaths because of change in population growth.

${ }^{d}$ Changes in deaths because of change in population aging.

${ }^{\mathrm{e}}$ Predicted values. 
(continued)

Table 2. Observed (1969-2014) and Predicted (2015-2020) Deaths From Heart Disease and Cancer, by Sex, Apportioned Into Changes Resulting From Population Risk, Population Growth, or Population Aging Relative to 1969 (Baseline) ${ }^{\mathrm{a}}$

\begin{tabular}{|c|c|c|c|c|c|c|c|c|}
\hline \multirow[b]{2}{*}{ Year of Death } & \multicolumn{4}{|c|}{ Male } & \multicolumn{4}{|c|}{ Female } \\
\hline & Total & Risk $^{b}$ & Growth $^{c}$ & Aging $^{d}$ & Total & Risk $^{b}$ & Growth $^{c}$ & Aging $^{d}$ \\
\hline $2017^{\mathrm{e}}$ & 321,107 & $-54,519$ & 77,990 & 122,232 & 285,294 & $-30,939$ & 69,618 & 100,255 \\
\hline $2018^{\mathrm{e}}$ & 326,119 & $-55,911$ & 78,728 & 127,898 & 288,432 & $-32,231$ & 70,265 & 104,038 \\
\hline $2020^{\mathrm{e}}$ & 335,283 & $-58,695$ & 80,066 & 138,508 & 294,297 & $-34,814$ & 71,466 & 111,285 \\
\hline Change from 1969 to $2020, \%$ & 91.1 & -33.5 & 45.6 & 79.0 & $101.1 \%$ & -23.8 & 48.8 & 76.0 \\
\hline
\end{tabular}

${ }^{a}$ Values are number unless otherwise noted.

${ }^{\mathrm{b}}$ Changes in deaths because of change in population risk of death.

${ }^{\mathrm{c}}$ Changes in deaths because of change in population growth.

${ }^{d}$ Changes in deaths because of change in population aging.

${ }^{\mathrm{e}}$ Predicted values. 